\title{
Infrared Dichroism Study of Segmented Polyurethaneurea with Triblock Polyether Soft Segments
}

\author{
Shinzo Kohjiya, Yuko Ikeda, Shinzo Yamashita, Mitsuhiro Shibayama,* \\ Tetsuo Kotani,* and Shunji Nomura* \\ Department of Material Science and ${ }^{*}$ Department of Polymer Science and Engineering, \\ Kyoto Institute of Technology, Matsugasaki, Kyoto 606, Japan
}

(Received November 30, 1990)

\begin{abstract}
Infrared (IR) dichroism study of segmented polyurethaneurea (SEUU) with ABA type triblock copolymer as a soft segment was carried out, where A stands for poly(oxyethylene) (PEO) and B stands for poly(oxytetramethylene) (PTMO). IR dichroism analysis of SEUU films under elongation suggested that the introduction of PEO units to the ends of PTMO brought about more aggregation of the hard segments, i.e., the better microphase separation in SEUU than segmented polyurethaneurea (SPUU) prepared from PTMO. Under uniaxial extension, the crystalline hard segment domain oriented transverse to the stretch direction at early stage, the degree of orientation being larger with the increase of PEO content. The larger was the PEO content, the better the microphase separation in SEUU.
\end{abstract}

KEY WORDS Segmented Polyurethaneurea / Infrared Dichroism / Microphase Separation / Triblock Copolyether / Poly(oxyethylene) / Poly(oxytetramethylene)

The relationship between structure and properties in block copolymers has been much focused in recent years with the increasing importance of thermoplastic elastomers. ${ }^{1,2}$ They include styrenic block copolymers (triblock copolymers) and segmented polyurethanes (multiblock copolymers). In order to understand their properties, it is necessary to elucidate their higher order structures, and the structural change according to elongation, because elastomers have a very large extensibility.

"Segmented" polyurethaneureas are multiblock copolymers that posses a general structure $(\mathrm{A}-\mathrm{B})_{n}$, where $\mathrm{A}$ is a hard segment and $B$ is a soft segment. ${ }^{3}$ The soft segment is usually a polyether or a polyester chain with molecular weight between several hundreds and a few thousand; the hard segment is formed from diisocyanate and diamine. The hard segments aggregate to form glassy or semi- crystalline domains in the soft segment matrix. Namely, the multiblock polymer undergoes microphase separation due to the chemical incompatibility between the polyether or polyester segment and the hard segment containing urethane or urea blocks. ${ }^{3,4} \mathrm{At}$ service temperature, the soft segment matrix is in a rubbery state, whereas the hard segment domain serves not only as a thermally reversible crosslink to give rubber elasticity and but also as a reinforcing filler to afford mechanical strength. The dependence of the properties of segmented polyurethaneurea on the chemical composition is now well recognized. ${ }^{5}$ Recently, there has been a growing appreciation that the physical properties are determined not only by the chemical structure but also by the extent of the phase separation between the soft and the hard segments. ${ }^{3}$ These two factors are closely related and a change in the chemical structure may alter the degree of phase 
separation.

Infrared (IR) spectroscopy is the principal method to characterize hydrogen bonding and is of use to investigate phase separated structures in polyurethaneurea. ${ }^{6,7}$ Hydrogen bonding may be formed between $\mathrm{NH}$ and $\mathrm{C}=\mathrm{O}$ groups and between $\mathrm{NH}$ and $\mathrm{C}-\mathrm{O}-\mathrm{C}$ groups. Both the frequency shifts and the intensity changes are caused by hydrogen bond formation. The intensity of each hydrogen bonded vibration can potentially yield the degree of phase separation in the polyurethaneurea. Orientation study by transmission IR dichroism has been recognized as a powerful technique to probe morphology and nonlinear viscoelastic behavior of segmented polyurethaneurea, as it is sensitive to changes in the microenvironments of the hard and the soft segments. ${ }^{8}$ Orientation of the soft segment can usually be followed using the asymmetric $\mathrm{CH}_{2}$ stretch vibration, the group residing primarily in the soft segment. ${ }^{8}$ Hard segment orientation can be characterized by the carbonyl group of the urea linkage and $\mathrm{NH}$ group located entirely in the hard segment. These bands split into free and hydrogen bonded components. ${ }^{9}$ By IR dichroism measurement, we can take advantage for the quantitative evaluation of orientation behavior of each segment separately.

Novel hydrophilic segmented polyurethaneureas (SEUU) were prepared from ABA type copolyether, i.e., poly(oxyethylene)- $b$-poly(oxytetramethylene)- $b$-poly(oxyethylene), ${ }^{10}$ which showed a good blood compatibility as well as excellent mechanical properties. ${ }^{11-15}$ The introduction of poly(oxyethylene) (PEO) unit to the ends of poly(oxytetramethylene) (PTMO) was found to result in the better microphase separation in SEUU. ${ }^{16}$ This morphological effect improved not only the antithrombogenicity but also the mechanical properties of SEUU. ${ }^{16}$

In this report, the morphology and the orientation behavior in SEUU are investigated by IR dichroism. The IR dichroism measurement will give important information on the change of the microphase separated structure with elongation, and will also be useful for consideration of the effect of morphology on blood compatibility.

\section{EXPERIMENTAL}

\section{Materials}

The materials used in this study were a series of segmented polyurethaneureas (SPUU and SEUU) prepared by the prepolymer method as described in the pevious paper. ${ }^{10}$ The polyether segments were PTMO for SPUU and PEO- $b$ PTMO- $b$-PEO for SEUU. The hand segment was formed by the reaction of isocyanate group from 4,4'-diphenylmethane diisocyanate (MDI) and amino group from ethylenediamine (ED). The chemical structures of segmented polyurethaneureas and their starting materials are shown in Figure 1. The characteristics of these polymers are given in Table I together

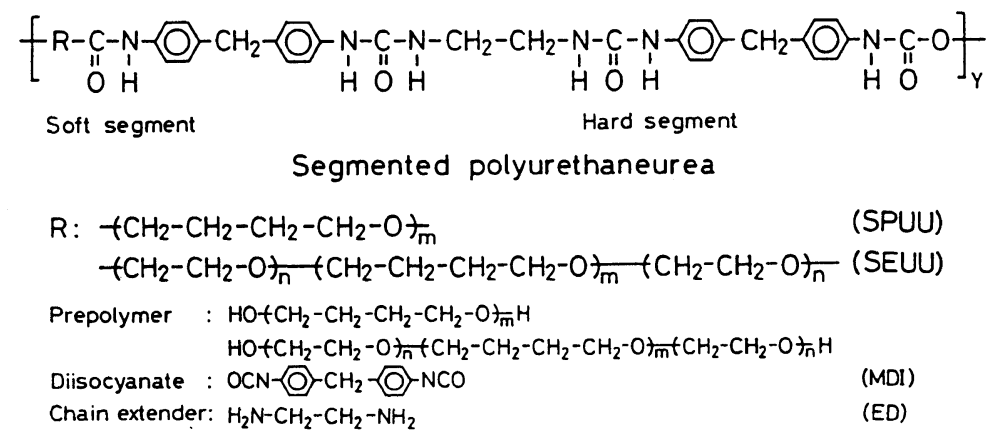

Figure 1. Chemical structures of segmented polyurethaneureas and their starting materials. 
with some molecular properties of the prepolymers. The number-average molecular weight $\left(M_{n}\right)$ of PTMO for SPUU and the PEO unit content for SEUU varied, while the hard block length was held constant. The larger the PEO unit content, the larger the soft segment length.

\section{Preparation of Thin Film}

$N, N^{\prime}$-Dimethylacetamide (DMAc) solution of a polymer $(4 \mathrm{wt} \%)$ was casted onto a Petri type glass dish followed by gradual solvent evaporation at $50^{\circ} \mathrm{C}$ under a reduced pressure $(<5 \mathrm{mmHg})$. The resulted film was dried in a vacuum oven at $50^{\circ} \mathrm{C}$ for several days to constant weight. The dried films were kept in a vacuum desicator at room temperature until just before the experiment. The thickness of the films was $c a .10 \mu \mathrm{m}$, which was measured by a microscope.

\section{Infrared Measurement}

IR absorption spectra were recorded on an IR spectrophotometer DS-403G (Japan Spectroscopic Co., Ltd.) with a resolution of $10 \mathrm{~cm}^{-1}$. Elongational strain was applied by a stretching device, and IR measurements were

Table I. Properties ${ }^{\mathrm{a}}$ of segmented polyurethaneurea

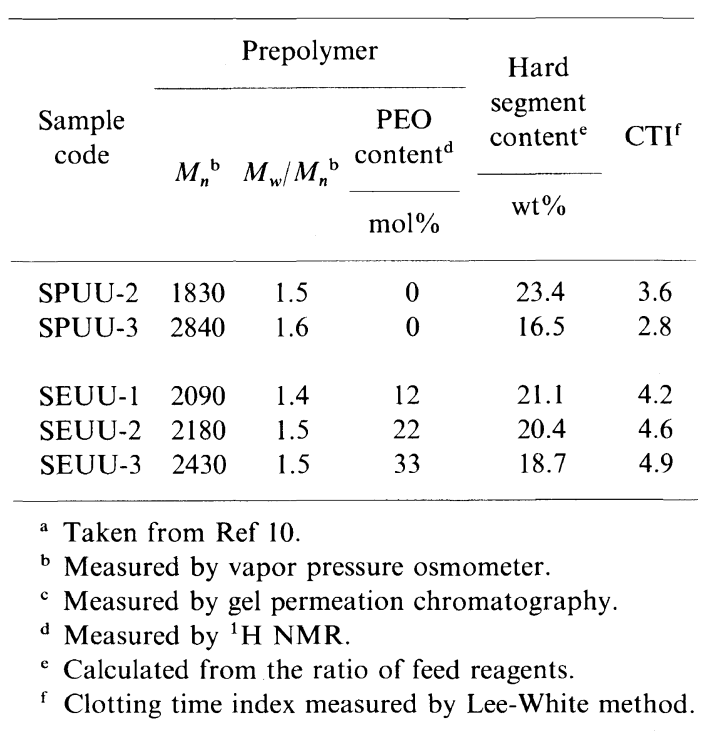

carried out using a silver chloride $(\mathrm{AgCl})$ polarizer inserted between the sample and the detector at $20^{\circ} \mathrm{C}$ and at $c a .65 \%$ relative humidity.

\section{RESULTS AND DISCUSSION}

\section{Infrared Analysis}

IR spectra of SPUUs and SEUUs are illustrated in Figure 2. The designation of several important bands is shown in the spectrum of SEUU-2, where "B" and "F" mean hydrogen bonded and free (not hydrogen bonded), respectively, and "UT" and "UA"

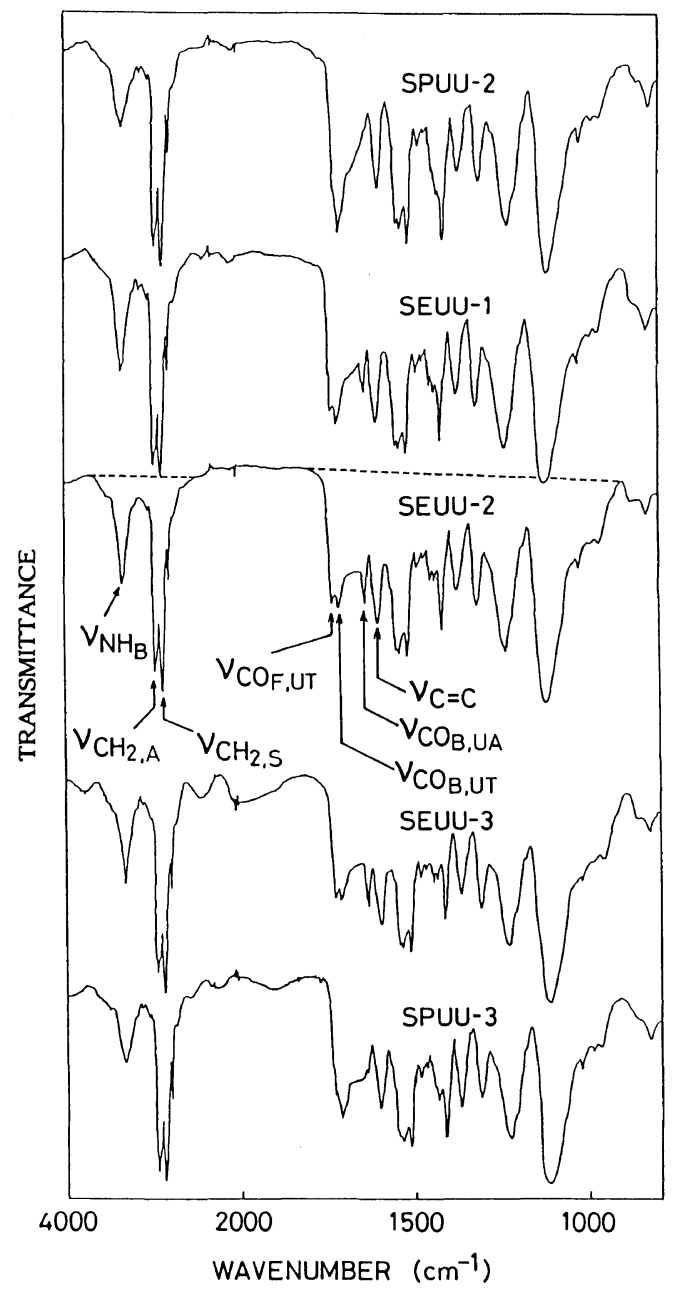

Figure 2. IR spectra of segmented polyurethaneureas. 
are abbreviations for urethane and urea, respectively. The absorption of the asymmetric $\mathrm{CH}_{2}$ stretching vibration $\left(\mathrm{CH}_{2, A}\right)$ and the symmetric $\mathrm{CH}_{2}$ stretching vibration $\left(\mathrm{CH}_{2, S}\right)$ appeared at $2960 \mathrm{~cm}^{-1}$ and $2870 \mathrm{~cm}^{-1}$, respectively. The $\mathrm{NH}$ absorption peak located at $3330 \mathrm{~cm}^{-1}\left(\mathrm{NH}_{\mathrm{B}}\right)$ indicates that most of the $\mathrm{NH}$ groups are hydrogen bonded, while the free $\mathrm{NH}$ absorption peak at $3445 \mathrm{~cm}^{-1}$ is negligible. In the region between $1620 \mathrm{~cm}^{-1}$ and $1750 \mathrm{~cm}^{-1}$, the absorption peak at $1730 \mathrm{~cm}^{-1}$ is due to the free urethane carbonyl group $\left(\mathrm{C}=\mathrm{O}_{\mathrm{F}, \mathrm{UT}}\right)$, the peak at $1710 \mathrm{~cm}^{-1}$ to the hydrogen bonded urethane carbonyl group $\left(\mathrm{C}=\mathrm{O}_{\mathrm{B}, \mathrm{UT}}\right)$, and the peak located at $1635 \mathrm{~cm}^{-1}$ is due to the hydrogen bonded urea carbonyl group $\left(\mathrm{C}=\mathrm{O}_{\mathrm{B}, \mathrm{UA}}\right)$. The absorption of free urea carbonyl group was reported to appear at $1695 \mathrm{~cm}^{-1},{ }^{17}$ but it was not clearly detected in every sample. In the spectra of SPUU-2 and SPUU-3, the peaks of $\mathrm{C}=\mathrm{O}_{\mathrm{F}, \mathrm{UT}}$ and $\mathrm{C}=\mathrm{O}_{\mathrm{B}, \mathrm{UA}}$ were not clearly observed, and several shoulders appeared between $1635 \mathrm{~cm}^{-1}$ and $1695 \mathrm{~cm}^{-1}$. These results suggest the segregation of the two segments in SPUU is not enough to differentiate all the peaks.

The relative absorbances of the bonded and the free carbonyl groups give the fraction of the hydrogen bonded urethane groups $\left(H_{\mathrm{UT}}\right)$ which is defined as,

$$
H_{\mathrm{UT}}=A(1710) /(A(1710)+A(1730))
$$

where $A(1710)$ and $A(1730)$ are the absorbances of the bonded and the free urethane carbonyl absorption peaks at $1710 \mathrm{~cm}^{-1}$ and $1730 \mathrm{~cm}^{-1}$, respectively. ${ }^{18-20}$ On the other hand, the ratio of the relative absorbance of the hydrogen bonded urea carbonyl absorption peak to that of the $\mathrm{C}=\mathrm{C}$ stretching absorption peak of the benzene ring at $1600 \mathrm{~cm}^{-1}$ is used as an index of the degree of the hydrogen bond of the urea carbonyl groups in the hard segments. That is to say, the ratio that can be used as an index of the cohesive force of the hard segments $\left(C_{\mathrm{h}}\right)$ is given by 19,20
Table II. Results of IR and DSC measurements

\begin{tabular}{|c|c|c|c|}
\hline \multirow{3}{*}{$\begin{array}{l}\text { Sample } \\
\text { code }\end{array}$} & \multicolumn{2}{|c|}{ IR } & \multirow{2}{*}{$\frac{\mathrm{DSC}^{\mathrm{c}}}{\Delta Q^{\mathrm{d}}}$} \\
\hline & $H_{\mathrm{UT}}^{\mathrm{a}}$ & $C_{h}{ }^{\mathrm{b}}$ & \\
\hline & & & $\mathrm{mj} \mathrm{mg}^{-1}$ \\
\hline SPUU-2 & 0.623 & 0.546 & 4.23 \\
\hline SPUU-3 & 0.573 & 0.731 & 6.38 \\
\hline SEUU-1 & 0.544 & 0.698 & 9.23 \\
\hline SEUU-2 & 0.512 & 0.789 & 11.43 \\
\hline SEUU-3 & 0.505 & 0.806 & 15.35 \\
\hline
\end{tabular}

a The fraction of the hydrogen bond in urethane groups. See eq 1.

b The cohesive index of the hard segments. See eq 2 .

c Calculated from the DSC curves of Ref 10.

d The heat of fusion of the hard segment domains.

$$
C_{\mathrm{h}}=A(1640) / A(1600)
$$

where $A(1640)$ and $A(1600)$ are the absorbances at $1640 \mathrm{~cm}^{-1}$ and at $1600 \mathrm{~cm}^{-1}$, respectively. $H_{\mathrm{UT}}$ and $C_{\mathrm{h}}$ were calculated and listed in Table II.

$C_{\mathrm{h}}$ of SEUU was larger than that of SPUU, and the order of $C_{\mathrm{h}}$ is SEUU-3 $>$ SEUU$2>$ SEUU- $1>$ SPUU-3 $>$ SPUU-2. This order suggests that the aggregation of the hard segments is more promoted in SEUU than SPUU, and the degree of their aggregation increases with the increase of PEO contents. In a study on segmented polyurethaneureas with polyether soft segments, the microphase separated structure was found to become more distinct with the increase of molecular weight of polyether in the soft segment. ${ }^{21}$ In SEUU, as the increase of PEO content is accompanied by the increase of $M_{n}$, both factors contributed to the microphase separation. However, $C_{\mathrm{h}}$ 's of SEUUs were larger than that of SPUU-3 with PTMO segments whose $M_{n}$ is 2840 . This result apparently suggests the effect of PEO units on morphology. On the contrary to $C_{\mathrm{h}}$, $H_{\mathrm{UT}}$ decreased in the opposite order of $C_{\mathrm{h}}$, i.e., SEUU-3 < SEUU- $2<$ SEUU- $1<$ SPUU-3 $<$ SPUU-2. Generally, it has been known that the better the microphase separation, the larger 
the $C_{\mathrm{h}}$, and the smaller the $H_{\mathrm{UT}}{ }^{20}$ Therefore, the IR analysis suggests that the presence of PEO units brought about more aggregation of the hard segments, i.e., better microphase separation in SEUU.

\section{Infrared Dichroism Analysis}

Analytical procedure for segmented polyurethaneurea The use of IR dichroism involves orienting a sample and measuring the absorbances of selected bands with radiations polarized perpendicular and parallel to the orientation direction. If the transition moment vector of a particular vibration has been preferentially aligned, the two absorbances ( $A_{\perp}$ and $A_{\|}$) will not be equal and the dichroic ratio $(D)$ may be calculated with the following eq 3 .

$$
D=A_{\perp} / A_{\|}
$$

$A_{\perp}$ and $A_{\|}$are the absorbances measured with radiation polarized perpendicular and parallel to the stretching direction, respectively. The dichroic ratio can be related to an orientation function $\left(F^{D}\right) .^{21}$

$$
F^{D}=(1-D) /(1+2 D)
$$

Several functional groups were used to conduct segmental orientation analysis in the soft and the hard segment domains of the segmented polyurethaneurea in this study. They include (1) the asymmetric $\mathrm{CH}_{2}$ stretching band at $2940 \mathrm{~cm}^{-1}$, which is a measure of soft segment orientation, (2) the $\mathrm{C}=\mathrm{O}$ stretching band at $1640 \mathrm{~cm}^{-1}$, a measure of the orientation of urea linkages within the hard segment domains, and (3) the $\mathrm{NH}$ band at $3317 \mathrm{~cm}^{-1}$, which characterizes the average hard segment orientation. The transition moment vectors of asymmetric vibration of $\mathrm{CH}_{2}, \mathrm{C}=\mathrm{O}$ and $\mathrm{NH}$ stretching bands are reported to be oriented by about $90^{\circ}, 78^{\circ}$, and $90^{\circ}$, respectively, with respect to the segment (or the chain) axes. ${ }^{8,19}$ According to the above definition, the positive $F^{D}$ means the negative (transverse) orientation of the corresponding segments axis and the transition moments for the perpendicular dichroism. For the simplicity in data manipulation, straight base lines were

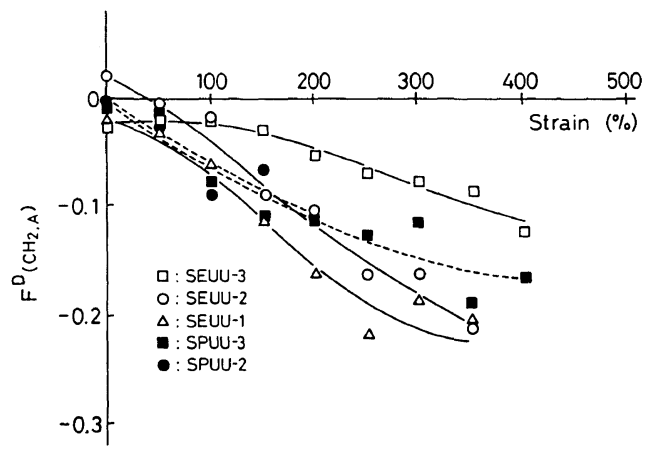

Figure 3. Elongation dependence of the orientation function of asymmetric $\mathrm{CH}_{2}$ for segmented polyurethaneureas

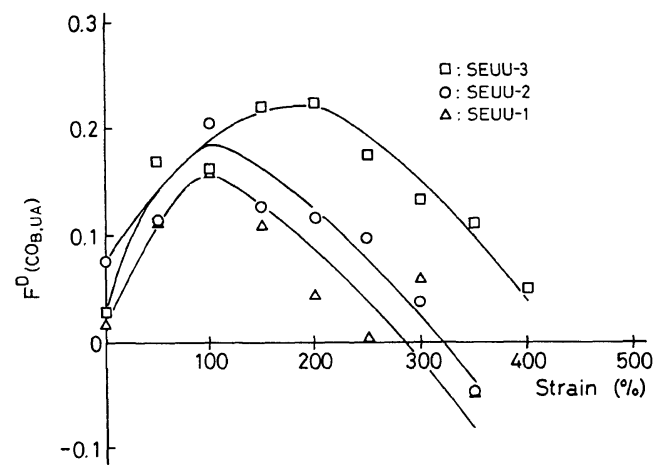

Figure 4. Elongation dependence of the orientation function of hydrogen bonded $\mathrm{C}=\mathrm{O}$ urea for segmented polyurethaneureas.

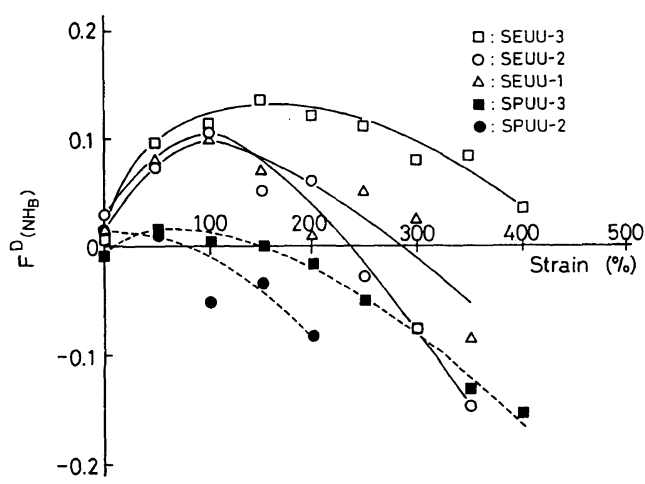

Figure 5. Elongation dependence of the orientation function of hydrogen bonded NH for segmented polyurethaneureas. 
assumed at range of $3700 \sim 2450 \mathrm{~cm}^{-1}$ for the $\mathrm{NH}$ and the asymmetric $\mathrm{CH}_{2}$ band, and of $1800 \sim 900 \mathrm{~cm}^{-1}$ for the $\mathrm{C}=\mathrm{O}$ stretching band.

Figures 3, 4, and 5 show the elongation dependence of the orientations of $\mathrm{CH}_{2, \mathrm{~A}}$, $\mathrm{C}=\mathrm{O}_{\mathrm{B}, \mathrm{UA}}$ and $\mathrm{NH}_{\mathrm{B}}$, respectively. In Figure 4, $F^{D}\left(\mathrm{C}=\mathrm{O}_{\mathrm{B}, \mathrm{UA}}\right)$ curves of SPUU-2 and SPUU-3 were not displayed because the peaks of their $\mathrm{C}=\mathrm{O}_{\mathrm{B}, \mathrm{UA}}$ did not appear clearly as shown in Figure 2.

Soft Segment Orientation Figure 3 shows the soft segment orientation behavior plotted against elongation for SEUUs and SPUUs. The positive orientation to the direction of stretch was observed in every sample. The changes of the orientation factors are less compared with those of hard segments. In SEUU series, the larger $F^{D}\left(\mathrm{CH}_{2, \mathrm{~A}}\right)$ was observed with the formation of the rigid hard segment domain. This observation suggests that the soft segment orientation of SEUU-3 was much affected by the hard segment domains, which may be explained by assuming that the microphase separation in SEUU-3 was the most complete one, and its hard segment domain was most rigid among the segmented polyurethaneureas used in this study.

Hard Segment Orientation Studies The orientation behavior of $\mathrm{C}=\mathrm{O}_{\mathrm{B}, \mathrm{UA}}$ and $\mathrm{NH}_{\mathrm{B}}$ gave important information on the change of the hard segment domains under uniaxial extension. Both in Figures 4 and 5 the hard segment domains were found to initially orient transverse to the stretch direction, and after reaching the maximal orientations their crystalline regions gradually broke up with increasing strain. Then, they became to orient positively with further elongation after passing the maximum of the negative orientation. It is also apparent that the larger the PEO content, the more negative the oreintation functions of $\mathrm{C}=\mathrm{O}_{\mathrm{B}, \mathrm{UA}}$ and $\mathrm{NH}_{\mathrm{B}}$ among the samples of 12 to $33 \mathrm{~mol} \%$ PEO content. In addition, the elongation at the maximum of the negative orientation became larger with the increase of PEO content. On the contrary the transverse orietnation of SPUU-3 was very small and that of SPUU-2 was not clearly detected as shown in Figure 5. Generally the microphase separation of segmented poly(ether urethaneurea) was known to be promoted by the increase of the molecular weight of soft segment. ${ }^{22}$ Therefore, from the transverse oreintation of SPUU-3 and SEUUs, the effect of the molecular weight on SEUU is concluded to be smaller than that of the presence of PEO units at the ends of PTMO.

The combination of the negative orientation of the hard segments and the positive orientation of the soft segment at low elongation has been widely observed, ${ }^{9,17,18}$ and a few mechanisms to explain this orientation behavior have been proposed. ${ }^{18,23,24}$ However, the essence of the mechanisms is not much different from each other. Namely, at relatively small elongation, the crystalline lamellae or glassy domains would be taken as orientation units floating in a matrix of the soft segments. In these units, the lamellar axis should be the principal orientation axis which gives its positive orientation. Because the principal axis of urethane or urethaneurea linkage is perpendicular to the axis of lamellae or glassy domains, the initial lamellar orientation results in the negative orientation of hard segments. At relatively large elongations, on the other hand, the oriented lmellae would disintegrate into small fragments. Then, the hard segment axis turns out to be the principal orientation axis giving its positive orientation.

To support the observations on SPUU and SEUU, it is useful to compare the heat of fusions $\left(\Delta Q_{\mathrm{h}}\right)$ of the hard segment domain in segmented polyurethaneurea which was obtained from DSC measurements reported. ${ }^{10}$ The value of $\Delta Q_{\mathrm{h}}$ shows the degree of the hard segment crystallinity, i.e., the larger the $\Delta Q_{\mathrm{h}}$, the more rigid hard segment was formed. The values of $\Delta Q_{\mathrm{h}}$ for the present polyurethaneureas listed in Table II. $\Delta Q_{\mathrm{h}}$ of SPUU-2 was smaller than that of SPUU-3. This result 
suggested the aggregation of the hard segment in SPUU-3 was better than that of SPUU-2, which is in accord with the results of IR and IR dichroism studies. $\Delta Q_{\mathrm{h}}$ 's of SEUUs $\left(M_{n}\right.$ of soft segment $=2090 \sim 2430$ ) were larger than that of SPUU-3 whose $M_{n}$ of soft segment is 2830 , and $\Delta Q_{\mathrm{h}}$ also became larger with the increase of PEO content. Table II suggests that SEUU-3 had the most crystalline domain, i.e., the most rigid hard segment domain among SEUUs. These results suggest that the aggregation of the hard segments was most promoted in SEUU-3 whose oxyethylene unit content was the highest among SEUUs.

In order to explain this effect of oxyethylene units in the ends of PTMO segment, it is assumed that oxyethylene $(\mathrm{C}-\mathrm{C}-\mathrm{O})$ units have a larger mobility than oxytetramethylene (C-C-C-C-O) units in the DMAc solution. This assumption is based on that the rotations along $\mathrm{C}-\mathrm{O}-\mathrm{C}$ bonds are easier than $\mathrm{C}-\mathrm{C}-\mathrm{C}$ bonds, because the presence of ether oxygen stabilizes gauche conformation. ${ }^{25}$ Additionally, the fraction of $\mathrm{C}-\mathrm{O}-\mathrm{C}$ bonds is larger in PEO than PTMO. In the preparation of polymer film by solution casting in this study, it is considered that the higher the mobility of polymer segment in DMAc solution, and the larger the time until the mobility of polymer chain was frozen, the more the microphase separation was pronounced. The difference of solubility might also affect the mobility of the segments in the solution. Namely, solubility paramerer $(\delta)$ of DMAc is $10.8^{26}$ and is nearer to that of PEO units $\left(\delta ; 9.8^{27}\right)$ than that of PTMO units $\left(\delta ; 9.2^{26}\right)$. These factors explain the reasons why the microphase separation of SEUUs was more pronounced by the introduction of PEO units compared with that of SPUU.

\section{CONCLUSION}

The IR analyses suggests that the introduction of PEO units has promoted the microphase separation in SEUU, which was in agreement with the results of DSC, dynamic mechanical measurement and SAXS. The orientation behavior of the soft and the hard segments was measured under uniaxial extension by IR dichroism. Initially, the crystalline hard segment domains oriented transverse (negative) to the stretch direction. The crystalline regions gradually broke up with increasing strain, and they began to positively orient to the stretch direction. The larger the PEO content, the more negative orientation continued to the higher elongation, which is explained by assuming that the introduction of PEO units to the ends of PTMO chain resulted in the more aggregation of hard segments to form the crystalline regions in SEUU. The soft segment orientation was positive to stretch direction in every sample.

\section{REFERENCES}

1. N. R. Legge, G. Holden, and H. E. Schroeder, Ed., "Thermoplastic Elastomers," Hanser, Munich, 1987.

2. S. Kohjiya, Zairyou, 39, 1173 (1990).

3. R. P. Redman, "Developments in Polyurethane-1," J. M. Buist, Ed., Applied Science Publishers Ltd., London, 1978, Chapter 3.

4. W. Meckel, W. Goyert, and W. Wieder, "Thermoplastic Elastomers,” N. R. Legge, G. Holden, and H. E. Schroeder, Ed., Hanser, Munich, 1987, Chapter 2.

5. Y. Ikeda and S. Kohjiya, Nihon Gomu Kyokaishi, 62, 357 (1989).

6. R. Bonart, L. Morbitzer, and E. H. Muller, $J$. Macromol. Sci. Phys., B9, 447 (1974).

7. D. O. Hummel, G. Ellinghorst, and H.-D. Stenzenberger, Angew. Makromol. Chem., 82, 129 (1979).

8. G. M. Esters, R. W. Seymour, and S. L. Cooper, Macromolecules, 4, 452 (1971).

9. R. W. Seymour, G. M. Esters, and S. L. Cooper, Macromolecules, 3, 579 (1970).

10. Y. Ikeda, S. Kohjiya, S. Yamashita, N. Yamamoto, K. Hayashi, and I. Yamashita, Nihon Kagaku Kaishi, 699 (1986).

11. S. Kohijiya, Y. Ikeda, S. Yamashita, K. Hayashi, N. Yamamoto, and I. Yamashita, Nihon Gomu Kyokaishi, 59, 685 (1986).

12. Y. Ikeda, S. Kohjiya, S. Yamashita, H. Fukumura, and S. Yoshikawa, Polym. J., 20, 273 (1988).

13. S. Kohjiya, S. Takesako, Y. Ikeda, and S. Yamashita, Polym. Bull., 23, 299 (1990).

14. Y. Ikeda, S. Kohjiya, S. Takesako, and S. Yamashita, Biomaterials, 11, 553 (1990).

15. Y. Ikeda, S. Kohjiya, S. Yamashita, and $\mathbf{H}$. 


\section{S. KoHJiYa et al.}

Fukumura, J. Mater. Sci., Mater. in Medicine, in press.

16. Y. Ikeda, S. Kohjiya, S. Yamashita, H. Hayashi, and T. Okuno, Nihon Reoroji Gakkaishi, 18, 12 (1990).

17. H. Ishihara, I. Kimura, K. Saito, and H. Ono, $J$. Macromol. Sci. Phys., B10, 591 (1974).

18. I. Kimura and H. Ishihara, "Kobunshi Bussei to Bunshi Kouzou,” Kagaku Zokan 58, M. Nagasawa, and Y. Yamashita, Ed., Kagakudojin, Kyoto, 1973, p 208.

19. C. B. Wang and S. L. Cooper, Macromolecules, 16, 775 (1983).

20. A. Takahara, J. Tashita, T. Kajiyama, and M. Takayanagi, Kobunshi Ronbunshu, 39, 203 (1982).

21. B. E. Read, "Structure and Properties of Oriented Polymers," I. M. Ward, Ed., Applied Science, London, 1975, p 150.
22. A. Takahara, J. Tashita, Y. Kajiyama, M. Takayanagi, and W. J. MacKnight, Polymer, 26, 987 (1985).

23. F. Hoffman and R. Bonart, Macromol. Sci., 184, 1529 (1983).

24. I. Kimura, H. Ishihara, H. Ono, N. Yoshihara, S. Nomura, and H. Kawai, Macromolecules, 7, 355 (1974).

25. P. J. Flory, "Statistical Mechanics of Chain Molecules," John Wiley \& Sons, New York, 1971, Chapter 3.

26. D. W. Vankrevelen and P. J. Hoftyzer, Ed., "Properties of Polymers," Elsevier, Amsterdam, 1976.

27. J. Brandrup and E. H. Immergut, "Polymer Handbook," Third ed., John Wiley \& Sons, New York, 1989, p 555. 